\title{
Relationships between Floral Morphology, Breeding Behavior, and Flower Longevity in Easter Cactus
}

\author{
Renate Karle $^{1}$ and Thomas H. Boyle ${ }^{2}$ \\ Department of Plant and Soil Sciences, French Hall, University of Massachusetts, Amherst, MA 01003
}

\begin{abstract}
AdDitional INDEX wORDS. Hatiora $\times$ graeseri, pollen tube growth, self-incompatibility, senescence, silver thiosulfate
Abstract. The effects of floral morphology and breeding behavior on flower longevity were investigated in Easter cactus [Hatiora $\times$ graeseri (Werderm.) Barthlott)]. Four clones were studied: two diploid $(n=11)$ clones ('Evita' and 'Purple Pride') that were highly self-incompatible (SI), and two cytochimeras (diploid epidermis and tetraploid subepidermis) that were recovered from the diploid cultivars, both of which were self-compatible (SC). The clones exhibited differences in the stage of floral development in which autogamy commenced. Autogamy commenced on the day of anthesis in the two 'Evita' clones and occurred $\approx \mathbf{5}$ days after anthesis in the 'Purple Pride' cytochimera. In the 'Purple Pride' diploid clone, anthers and stigmatic lobes remained spatially separated during the period from anthesis to senescence. Examination of styles collected from senesced, undisturbed flowers showed that few pollen tubes traversed to the base of the styles for the two SI diploid clones, whereas large numbers of pollen tubes were present at the base of the styles for the two SC cytochimeras. Flower longevity for the 'Evita' cytochimera was significantly less than for 'Evita' diploid, but the diploid and cytochimeral clones of 'Purple Pride' exhibited similar flower longevities. Application of 2 mu silver thiosulfate, an inhibitor of ethylene $\left(\mathrm{C}_{2} \mathrm{H}_{4}\right)$ action, did not affect flower longevity of 'Evita' cytochimera. Our results show that flower longevity in Easter cactus is influenced by breeding behavior and the stage of floral development at which autogamy commences.
\end{abstract}

Easter cactus is a succulent epiphytic shrub that is cultivated as a flowering potted crop (Boyle, 1997a). Individual flowers of Easter cactus last from 7 to $12 \mathrm{~d}$ at $20^{\circ} \mathrm{C}$ (Scott et al., 1994). The initial symptom of floral senescence in Easter cactus is wilting of the perianth, and is normally followed by abscission of the entire flower (Scott et al., 1994). In a study of eight Easter cactus cultivars, Scott et al. (1994) found that flowers of 'Mira' lasted only $6.7 \mathrm{~d}$ whereas those of the seven other cultivars lasted 9.6 to $12.2 \mathrm{~d}$. Flowers of 'Mira' senesced but did not abscise, and ovaries eventually differentiated into fruit that contained viable seeds. Flowers of the seven other cultivars senesced and then abscised without setting fruit. These results imply that fruit set may affect floral longevity in Easter cactus.

Self-incompatibility (SI) is a genetically controlled mechanism that prevents or hinders self-fertilization in fertile hermaphroditic plants when they are selfed or outcrossed to another plant with an identical incompatibility phenotype (de Nettancourt, 1977). Studies with SI clones of Petunia $\times$ hybrida and P. inflata have shown that selfed flowers senesce later than compatibly crossed flowers (Ascher, 1984; Gilissen, 1977; Singh et al., 1992), suggesting that SI may weaken the effect of pollination on flower senescence, thus ensuring that flowers remain open for legitimate (cross) pollen after illegitimate (self) pollen has been deposited on the stigma. Most cultivars of Easter cactus are SI (Boyle et al., 1994; Ganders, 1976), but it is not known if SI has any influence on flower longevity. Recent work (Boyle, 1997b) has shown that the SI system in the Cactaceae is monogenic and under gametophytic control.

Self-compatibility (SC) is frequently encountered among artificially induced tetraploids or natural tetraploid relatives of diploid species that exhibit one-locus, gametophytic SI (de Nettancourt, 1977). Autotetraploidy occurs within the Cactaceae

Received for publication 29 June 1998. Accepted for publication 8 Feb. 1999 Publication 3222 of the Massachusetts Agricultural Experiment Station. The cost of publishing this paper was defrayed in part by the payment of page charges. Under postal regulations, this paper therefore must be hereby marked advertisement solely to indicate this fact.

${ }^{1}$ Graduate research assistant.

${ }^{2}$ Associate professor. To whom reprint requests should be addressed; e-mail tboyle@pssci.umass.edu. and is often associated with an SC breeding system (Ross, 1981).

The objectives of the present investigation were to study flower longevity in diploid (SI) and cytochimeral (SC) clones of 'Evita' and 'Purple Pride' Easter cactus, and determine if flower longevity was influenced by floral morphology or breeding behavior.

\section{Materials and Methods}

Plant material. Four vegetatively propagated clones were used for study. Two of the clones ('Evita' and 'Purple Pride') were diploid $(n=11)$ and highly SI (Boyle et al., 1994; Karle, 1996). Spontaneous chromosome doubling occurred in shoot apices of both cultivars and yielded stable periclinal cytochimeras possessing a diploid epidermis and tetraploid subepidermis (Karle, 1996). The cytochimeras produced functional disomic gametes $(n=22)$ and were SC (Karle, 1996). Henceforth, the two diploid clones will be referred to as 'Evita' original and 'Purple Pride' original, and the two chimeral clones will be referred to as 'Evita' variant and 'Purple Pride' variant.

GENERAL PROCEDURES. Experiments were performed either in a glasshouse or in a growth chamber (model I-35LVL; Percival Scientific, Boone, Iowa). Glasshouse conditions were $18 \pm 2{ }^{\circ} \mathrm{C}$ nights $/ 20 \pm 2{ }^{\circ} \mathrm{C} \mathrm{d}$ and long-day (LD) photoperiods. LDs were achieved by supplementing natural daylengths with incandescent irradiation $\left(3 \mu \mathrm{mol} \cdot \mathrm{m}^{-2} \cdot \mathrm{s}^{-1}\right)$ from 1600 to $2200 \mathrm{HR}$. Shading compound (Kool Ray; Continental Products Co., Euclid, Ohio) was applied to the glass to maintain the photosynthetic photon flux (PPF) below $600 \mu \mathrm{mol} \cdot \mathrm{m}^{-2} \cdot \mathrm{s}^{-1}$. Growth chamber conditions were $20 \pm 1{ }^{\circ} \mathrm{C}, 75 \% \pm 5 \%$ relative humidity $(\mathrm{RH})$, and $50 \pm 8$ $\mu \mathrm{mol} \cdot \mathrm{m}^{-2} \cdot \mathrm{s}^{-1} \mathrm{PPF}$ for $12 \mathrm{~h}$ daily from cool-white fluorescent lamps. Air temperatures and PPF were monitored with a datalogger (LI-1000; LI-COR, Lincoln, Neb.) using an aspirated thermistor (LI-1000-16) and quantum sensor (LI-190SA). RH was monitored with a hygrometer (SPER Scientific Ltd., Tempe, Ariz.).

Whole phylloclades were propagated in 72-cell plastic trays, using one phylloclade per $36-\mathrm{cm}^{3}$ cell. Rooted phylloclades were transplanted singly into $230-\mathrm{cm}^{3}(7.5-\mathrm{cm})$ plastic pots. A com- 
mercial medium composed of sphagnum peat, perlite, and vermiculite (Fafard Growing Mix No. 2; Conrad Fafard, Springfield, Mass.) was used for propagation and growing. Plants kept in the glasshouse were fertilized at every watering with $20 \mathrm{~N}-4.3 \mathrm{P}$ $16.6 \mathrm{~K}\left(12 \% \mathrm{NO}_{3}-\mathrm{N}, 8 \% \mathrm{NH}_{4}-\mathrm{N}\right)$ at $180 \mathrm{mg} \mathrm{N} / \mathrm{L}$. Fertilization began after phylloclades were rooted and continued throughout the experiments. During growth chamber experiments, plants were irrigated with tap water $\left(\leq 0.12 \mathrm{dS} \cdot \mathrm{m}^{-1}\right.$ electrical conductivity). Six experiments were performed.

LONGEVITY OF UNDISTURBED FLOWERS (EXPT. 1). Plants of the original and variant clones of 'Evita' and 'Purple Pride' with several mature flower buds $(\approx 1$ to $2 \mathrm{~d}$ from anthesis) were transferred to a growth chamber. Flowers were tagged on the day of anthesis, and were observed daily between 1100 and $1300 \mathrm{HR}$. Flower longevity (number of days from anthesis to senescence) was recorded for 20 flowers per clone. The morphological criteria described by Scott et al. (1994) were used to ascertain the commencement of anthesis and senescence.

KINETIC STUDY OF FLORAL MORPHOLOGY (EXPT. 2). The spatial arrangement of the anthers and stigmatic lobes (= herkogamy) was studied in the original and variant clones of 'Evita' and 'Purple Pride'. At anthesis and senescence, data were collected on the minimum distance (in $\mathrm{mm}$ ) between the uppermost anther and the most proximal part of the stigma (= the base or tips of the stigmatic lobes). For the variant clones, measurements were also made during the middle stage of floral development (Scott et al., 1994). Data were collected on ten flowers per clone. Other floral attributes that were recorded included the number of days from anthesis until the commencement of 1) pollen shedding and 2) autogamy (self-pollination).

FRUIT AND SEED SET IN ISOLATED PLANTS (EXPT. 3). To determine if flowers would set fruit without manual pollination, three plants of each clone were enclosed within $1.2 \times 0.9 \times 0.7 \mathrm{~m}$ pollination cages covered with polypropylene woven fabric $(\approx 8$ threads $/ \mathrm{cm})$. Each pollination cage contained only one clone, and cages were separated by a minimum distance of $2 \mathrm{~m}$. Before the start of the experiment, opened flowers were removed and the number of unopened buds were counted on each plant. Plants were irrigated at the surface of the growing medium so as to avoid wetting the flowers. At $120 \mathrm{~d}$ after pollination, fruit that remained on the plants were counted, and percent fruit set was calculated for each clone. Fruit were harvested the same day and seeds were cleaned by vacuum extraction (Boyle, 1994). Seeds were germinated using procedures described by Boyle et al. (1994). The numbers of germinated seeds were recorded at $30 \mathrm{~d}$ after sowing. A seed was considered germinated upon emergence of the radicle.

Microscopal aNALYSIS OF POLLEN TUBE GROWTH (EXPT. 4). Glasshouse-grown plants of the original and variant clones of 'Evita' and 'Purple Pride' were separated from other clones by a minimum distance of $2 \mathrm{~m}$. Plants were not disturbed and flowers were allowed to naturally self-pollinate. Styles were collected from senesced flowers, fixed in 3 ethanol : 1 glacial acetic acid ( $\mathrm{v} /$ v) for $\geq 24 \mathrm{~h}$, softened for $40 \mathrm{~min}$ at $100{ }^{\circ} \mathrm{C}$ in $10 \%$ (w/v) $\mathrm{Na}_{2} \mathrm{SO}_{3}$, stained overnight with $0.1 \%(\mathrm{w} / \mathrm{v})$ decolorized aniline blue in 0.1 $\mathrm{MK}_{3} \mathrm{PO}_{4}$ (Martin, 1959), and examined with a Zeiss epifluorescence microscope equipped with a 100-W high-pressure Hg lamp and a filter set for ultraviolet-violet waveband excitation (exciter filter BP 395-425, dichromatic beam splitter FT 425, and barrier filter LP 450). Ten styles were examined per clone.

INFLUENCE OF MANUAL POLLINATION ON FLOWER LONGEVITY (EXPT. 5). Budded plants of 'Evita' variant and 'Purple Pride' variant were transferred to a growth chamber. Flowers remained undisturbed or were manually self-pollinated on the day of anthe- sis. Flower longevity was determined as described earlier, using 20 flowers per treatment.

INFLUENCE OF SILVER THIOSULFATE AND STYLAR REMOVAL ON FLOWER LONGEVITY (EXPT. 6). Budded plants of 'Evita' variant were either sprayed with $2 \mathrm{~mm}$ silver thiosulfate [STS; $\mathrm{Ag}\left(\mathrm{S}_{2} \mathrm{O}_{3}\right)_{2}{ }^{3-}$ ] or deionized water. In a previous study (Han and Boyle, 1996), a 2 mM STS foliar spray was found to significantly reduce flower bud abscission and premature flower senescence due to $\mathrm{C}_{2} \mathrm{H}_{4}$ exposure. Solutions contained $1 \mathrm{~mL}$ Tween 20/L (polyoxyethylene sorbitan monolaurate) as a surfactant and were applied at a rate of $\approx 15 \mathrm{~mL} /$ plant. Plants were transferred to a growth chamber one day after sprays were applied. There were six flower treatments: intact flowers (controls) or removal of the entire style on the day of anthesis (day 0) or 1, 2, 3, or $4 \mathrm{~d}$ after anthesis. There were four replicate plants per treatment. Each flower treatment was applied to five flowers per plant. Styles were removed by grasping the stigmatic lobes and pulling tangentially to the flower. Flower longevity was determined as described previously. Styles that were removed 0 to $4 \mathrm{~d}$ after anthesis were fixed, softened, and stained as described in Expt. 4. Styles were also excised from control flowers on the day of senescence (day 8 or 9), and these were fixed and stained as described earlier. Styles were examined with an epifluorescence microscope. Ten styles were examined per flower treatment.

Data AnALYSIS. Data were analyzed by SAS Institute's (Cary, N.C.) General Linear Models (GLM) procedure. Flower longevity data in Expt. 6 demonstrated variance heterogeneity and were transformed $\left[\log _{10}(x+1)\right]$ before statistical analysis.

Table 1. Longevity of undisturbed flowers on the original and variant clones of 'Evita' and 'Purple Pride' Easter cactus.

\begin{tabular}{lc}
\hline Clone & $\begin{array}{c}\text { Flower longevity } \\
\text { (d) }\end{array}$ \\
\hline Evita & $11.5 \pm 1.1$ \\
$\quad$ Original & $8.3 \pm 0.7$ \\
Variant & $*$ \\
Significance & \\
Purple Pride & $10.8 \pm 0.8$ \\
Original & $11.4 \pm 0.7$ \\
Variant & NS \\
Significance &
\end{tabular}

$\overline{\mathrm{z}}$ Days from anthesis to commencement of senescence. Mean of 20 flowers \pm SE.

Ns, ${ }^{*}$ Nonsignificant or significant at $P=0.05$, respectively.

Table 2. Minimum distance between the uppermost anther and the most proximal part of the stigmatic lobe at anthesis, midlife and senescence in the original and variant clones of 'Evita' and 'Purple Pride' Easter cactus.

\begin{tabular}{lccc}
\hline \hline Clone & $\begin{array}{c}\text { Anthesis } \\
(\mathrm{mm})\end{array}$ & $\begin{array}{c}\text { Midlife }^{\mathrm{z}} \\
(\mathrm{mm})\end{array}$ & $\begin{array}{c}\text { Senescence } \\
(\mathrm{mm})\end{array}$ \\
\hline Evita & & & $-2.2 \pm 0.2$ \\
$\quad$ Original & $-1.4 \pm 0.1^{\mathrm{y}}$ & --- & $-4.4 \pm 0.2$ \\
$\quad$ Variant & $-3.1 \pm 0.2$ & $-3.2 \pm 0.3$ & \\
Purple Pride & & -- & $0.7 \pm 0.2$ \\
$\quad$ Original & $2.0 \pm 0.1$ & -- & $-1.2 \pm 0.1$ \\
$\quad$ Variant & $1.3 \pm 0.2$ & $0.0 \pm 0.3$ &
\end{tabular}

$\overline{\mathrm{z}}$ Midlife $=$ the fourth and fifth day after anthesis for 'Evita' variant and 'Purple Pride' variant, respectively.

yPositive values indicate spatial separation. Negative values indicate that the uppermost anther is in contact with or above the most proximal part of the stigmatic lobe. Mean of 10 flowers per treatment \pm SE. 


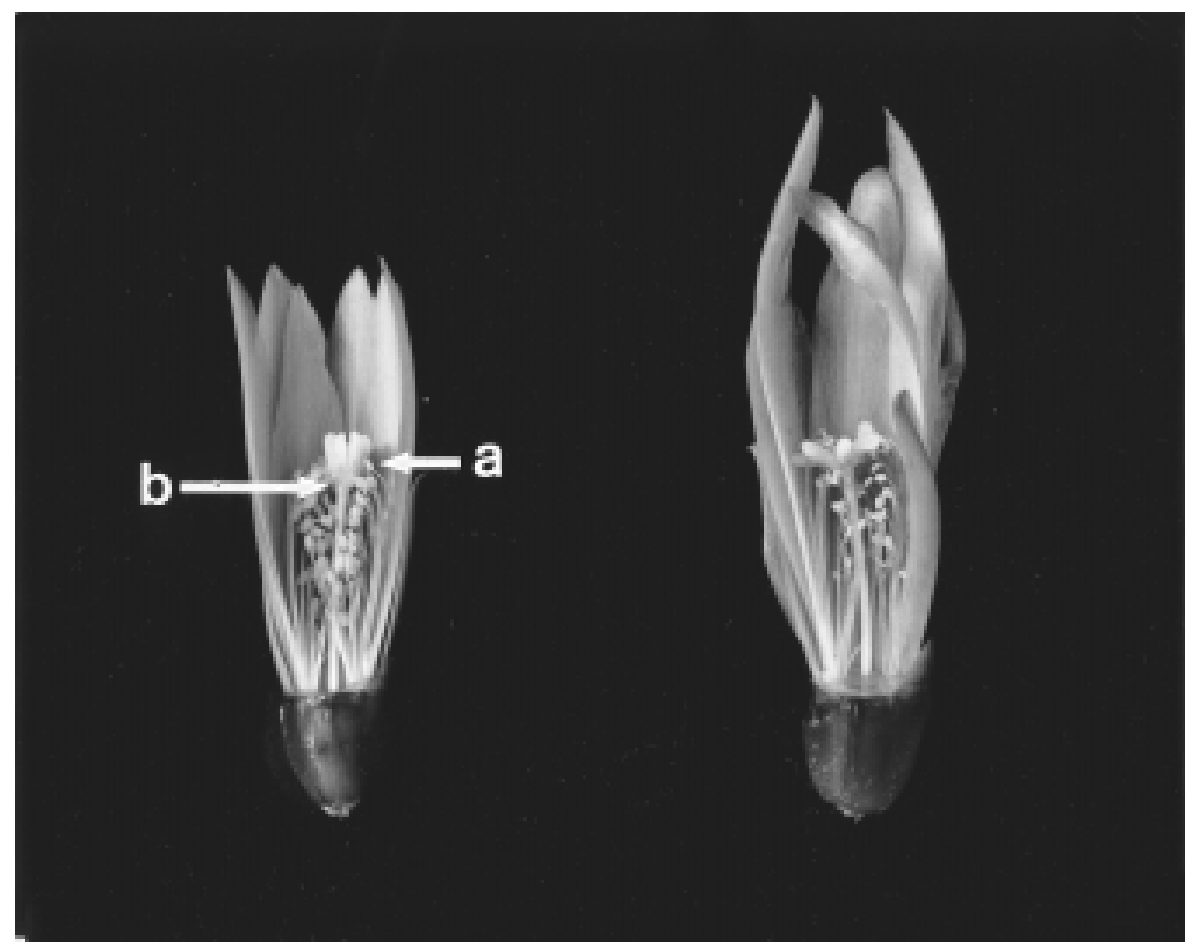

EXPERIMENT 5. Relative to the unpollinated controls, manual self-pollination did not affect flower longevity for 'Evita' variant but reduced flower longevity by $\approx 1$ day for 'Purple Pride' variant (Table 5).

EXPERIMENT 6. Flower longevity in 'Evita' variant was significantly affected by the flower treatments $(P<0.001)$ but was unaffected by application of STS $(P=0.29)$. The $\mathrm{STS} \times$ flower treatment interaction alsolacked significance $(P>0.05)$, and therefore the data from the STS treatments were pooled and reanalyzed by SAS's GLM procedure. The effect of stylar removal on flower longevity was dependent on the timing of detachment (Table 6). Compared to intact flowers, removal of the style on the day of anthesis (day 0) extended flower longevity whereas removal of the style on day 2,3 , or 4 decreased flower longevity. Intact flowers and those in which the styles were removed 1 day after anthesis were similar in longevity.

Few pollen tubes had traversed to the base of the style by day 1 , but the numbers increased markedly between day 1 and day 3 (Table 7). The numbers of pollen tubes ob-

Fig. 1. Longitudinally sectioned flowers of 'Evita' original on the day of anthesis (left) and day of senescence (right). The stigmatic lobes are erect at anthesis and reflexed at senescence; $\mathrm{a}=$ uppermost anther, $\mathrm{b}=$ base of stigmatic lobes.

\section{Results}

Experiment 1. Flowers of 'Evita' variant senesced earlier than those of 'Evita' original (Table 1). However, the original and variant clones of 'Purple Pride' did not exhibit significant differences in flower longevity (Table 1).

Experiment 2. Stigmatic lobe orientation and the spatial arrangement of the stigma and anthers changed between anthesis and senescence (Table 2). For all clones, stigmatic lobes were erect at anthesis but became reflexed as the flowers aged, thus increasing the likelihood of autogamy during the latter phase of flower development (Fig. 1). Anthers began to shed pollen on or about the day of anthesis in all clones. Autogamy commenced on the first day of anthesis in flowers of 'Evita' original and 'Evita' variant, but did not occur until about the fifth day after anthesis in flowers of 'Purple Pride' variant. In 'Purple Pride' original, anthers and stigmatic lobes remained in close proximity but not in direct contact from anthesis through senescence (Table 2).

ExPERIMENT 3. Caged plants of the two original clones failed to set fruit whereas caged plants of the two variant clones produced numerous fruit (Table 3). Each fruit collected from the variant clones contained $\approx 40$ to 50 viable seeds (Table 3 ).

EXPERIMENT 4. Undisturbed flowers of the original and variant 'Evita' and 'Purple Pride' clones that were collected at senescence contained numerous germinated pollen grains on the stigmatic surface. Most of the pollen grains were attached to the basal portion of the stigma lobes that were in direct contact with anthers. Despite the abundance of germinated pollen grains, relatively few pollen tubes extended to the base of the style in the original clones (Table 4). Pollen tube attrition in the SI original clones occurred primarily in the upper third of the style. Numerous pollen tubes were observed at the base of the style in the SC variant clones (Table 4). served at the base of the style on day 3 and day 4 were similar to those observed at senescence (Table 7).

Table 3. Percent fruit set and number of viable seeds per fruit for isolated plants of the original and variant clones of 'Evita' and 'Purple Pride' Easter cactus.

\begin{tabular}{lccc}
\hline \hline Clone & $\begin{array}{c}\text { Open flowers } \\
\text { (no./plant) }\end{array}$ & $\begin{array}{c}\text { Percent } \\
\text { fruit set }^{\mathrm{y}}\end{array}$ & $\begin{array}{c}\text { No. of viable } \\
\text { seeds/fruit }^{\mathrm{x}}\end{array}$ \\
\hline $\begin{array}{c}\text { Evita } \\
\text { Original }\end{array}$ & $\begin{array}{c}\text { 48.7 } \pm 8.7 \\
\text { Variant }\end{array}$ & 0 & --- \\
$\begin{array}{c}\text { Purple Pride } \\
\text { Original }\end{array}$ & $42.0 \pm 4.8$ & $44.4 \pm 14.6$ & $41.3 \pm 3.2$ \\
Variant & $33.0 \pm 1.5$ & $72.2 \pm 6.4$ & $-16.7 \pm 8.9$
\end{tabular}

${ }^{\mathrm{z}}$ Mean of three plants per treatment \pm SE.

$\mathrm{y}($ No. fruit set/no. opened flowers $) \times 100$. Mean of three plants per treatment \pm SE. Data collected $120 \mathrm{~d}$ after the last flower bud had opened. ${ }^{x}$ Mean of 10 fruit per treatment \pm SE. Data collected $30 \mathrm{~d}$ after seed sowing.

Table 4. Number of pollen tubes in undisturbed flowers of the original and variant clones of 'Evita' and 'Purple Pride' Easter cactus.

\begin{tabular}{lc}
\hline \hline Clone & $\begin{array}{c}\text { No. of pollen tubes } \\
\text { at the base of style }\end{array}$ \\
\hline Evita & $10.2 \pm 2.0$ \\
Original & $99.5 \pm 6.1$ \\
Variant & $* * *$ \\
$\quad$ Significance & \\
Purple Pride & $4.2 \pm 1.4$ \\
Original & $83.0 \pm 6.5$ \\
Variant & $* * *$ \\
Significance &
\end{tabular}

$\overline{{ }^{\mathrm{z}} \text { Mean of } 10 \text { styles per treatment } \pm \text { SE. Flowers collected on the day of }}$ senescence.

${ }^{* * * *}$ Significant at $P=0.001$. 
Table 5. Effect of pollination on flower longevity of the variant clones of 'Evita' and 'Purple Pride' Easter cactus.

\begin{tabular}{|c|c|c|}
\hline Clone & Treatment & $\begin{array}{l}\text { Flower longevity }{ }^{2} \\
\text { (d) }\end{array}$ \\
\hline \multirow[t]{2}{*}{ Evita variant } & Undisturbed flowers & $8.3 \pm 0.7$ \\
\hline & Pollinated at anthesis & $8.6 \pm 0.9$ \\
\hline Significance & & NS \\
\hline \multirow[t]{2}{*}{ Purple Pride variant } & Undisturbed flowers & $10.5 \pm 0.7$ \\
\hline & Pollinated at anthesis & $9.1 \pm 0.7$ \\
\hline \multicolumn{2}{|l|}{ Significance } & $*$ \\
\hline \multicolumn{3}{|c|}{$\begin{array}{l}{ }^{2} \text { Days from anthesis to commencement of senescence. Mean of } 20 \\
\text { flowers per treatment } \pm \text { SE. } \\
\text { Ns, }{ }^{*} \text { Nonsignificant or significant at } P=0.05 \text {, respectively. }\end{array}$} \\
\hline \multicolumn{3}{|c|}{$\begin{array}{l}\text { Table } 6 \text {. Effect of timing of stylar removal on flower longevity of 'Evita' } \\
\text { variant. }\end{array}$} \\
\hline
\end{tabular}

\begin{tabular}{lc}
\hline \hline Treatment & $\begin{array}{c}\text { Flower longevity } \\
(\mathrm{d})\end{array}$ \\
\hline Intact flower (control) & $8.7 \pm 0.1$ \\
Style removed on day 0 & $10.0 \pm 0.2^{*}$ \\
Style removed on day 1 & $9.0 \pm 0.2^{\mathrm{NS}}$ \\
Style removed on day 2 & $7.4 \pm 0.2^{*}$ \\
Style removed on day 3 & $7.3 \pm 0.2^{*}$ \\
Style removed on day 4 & $7.7 \pm 0.1^{*}$
\end{tabular}

${ }^{\mathrm{z}}$ Days from anthesis to commencement of senescence. Mean of 40 flowers per treatment \pm SE.

ns, ${ }^{*}$ Nonsignificant or significant by Dunnett's two-sided test $(\alpha=0.05)$, control vs. other treatments.

Table 7. Number of pollen tubes in styles of 'Evita' variant at different stages of flower development.

\begin{tabular}{lc}
\hline \hline $\begin{array}{l}\text { Stage of } \\
\text { flower development }\end{array}$ & $\begin{array}{c}\text { No. of pollen tubes } \\
\text { at the base of style }\end{array}$ \\
\hline Anthesis (day 0) & $0.4 \pm 0.5^{*}$ \\
Day 1 & $10.3 \pm 4.5^{*}$ \\
Day 2 & $41.7 \pm 6.5^{*}$ \\
Day 3 & $82.9 \pm 5.4^{\mathrm{NS}}$ \\
Day 4 & $92.0 \pm 10.1^{\mathrm{NS}}$ \\
Senescence (days 8-9) & $117.5 \pm 7.0$ \\
\hline "Mean of 10 styles per treatment \pm SE. \\
"Ns, Nonsignificant or significant by Dunnett's two-sided test $(\alpha=0.05)$, \\
days 8 and 9 vs. other treatments.
\end{tabular}

\section{Discussion}

Our results indicate that flower senescence is hastened in SC genotypes that self-pollinate early in floral development, but is not affected by the timing of self-pollination in SI genotypes. The 3 -d difference in flower longevity between the variant and original clones of 'Evita' implies that SI provides some protection against premature floral senescence that occurs in some SC genotypes. SI has been reported to have a similar effect on flower longevity in $P$. Xhybrida (Ascher, 1984; Gilissen, 1977) and $P$. inflata (Singh et al., 1992). Lack of SI may also explain why flowers of 'Mira', an SC cultivar, senesced earlier than seven other SI cultivars that were studied by Scott et al. (1994). Furthermore, our data indicate that flower morphology can influence flower longevity in Easter cactus. This is shown by comparing the responses of the variant clones of 'Evita' and 'Purple Pride', both of which were SC (Tables 3 and 4). For 'Evita' variant, autogamy commenced on the day of anthesis (Table 2) and flowers senesced earlier than those of the other clones examined in this study (Table 1). For 'Purple Pride' variant, autogamy commenced during the middle stage of floral development (Table 2), but flowers selfed on the day of anthesis senesced earlier than those that remained undisturbed (Table 5). These results imply that flower longevity among SC clones is determined by the stage of floral development in which autogamy commences, which in turn is dependent on the spatial arrangement of the anthers and stigmatic lobes.

Among the four clones examined in this study, 'Purple Pride' original displayed the greatest spatial separation between anthers and stigmatic lobes (Table 2). Although we did not observe autogamy within flowers of this clone, we did observe several pollen tubes at the base of styles collected from undisturbed flowers of 'Purple Pride' original (Table 4), indicating that the degree of spatial separation was insufficient to prevent the occurrence of some selfing. Anthers and stigmatic lobes may have come into direct contact during the diurnal movement of petals (nyctinasty) that occurs in flowers of Easter cactus (Scott el al., 1994). Autogamy in 'Purple Pride' original flowers is most likely to have occurred during the latter stage of floral development when the anthers and stigmatic lobes were in closest proximity (Table 2).

In $P$. Xhybrida, the signal that accelerates senescence in pollinated flowers is translocated through the style between 4 and $17 \mathrm{~h}$ after pollination (Gilissen and Hoekstra, 1984; Lovell et al., 1987). This signal arrives at the ovary before the pollen tubes, which normally require between 30 and $90 \mathrm{~h}$ to reach the ovary (Gilissen, 1977). A relevant question, therefore, is whether or not a stimulus that accelerates floral wilting exists independently of the pollen tubes in Easter cactus. Early flower senescence in 'Evita' variant was blocked by severing the style on the day of anthesis, a time when very few pollen tubes had traversed the style, but was not blocked by severing the style $\approx 24 \mathrm{~h}$ after anthesis (day 1), when $\approx 10$ pollen tubes had reached the base of the style (Tables 6 and 7). From these results, we cannot conclude with certainty that a signal independent of the pollen tubes triggers early flower senescence in 'Evita' variant. The fact that 'Evita' original and 'Evita' variant were similar in floral morphology (Table 2) but dissimilar in breeding behavior (Tables 3 and 4) and flower longevity (Table 1) indicates that, if a separate stimulus for early flower senescence does exist, it is not pollination per se.

Pollination-induced flower senescence in Cyclamen persicum (Halevy et al., 1984), Dianthus caryophyllus (Nichols and Frost, 1985), and $P$. ×hybrida (Whitehead et al., 1984) can be averted by pretreating cut flowers or intact plants with STS before pollination. However, application of $2 \mathrm{~mm}$ STS had no apparent effect on flower longevity of 'Evita' variant. These findings imply that flower senescence in 'Evita' variant is not caused by the action of $\mathrm{C}_{2} \mathrm{H}_{4}$ (Beyer, 1976). Flower senescence may have been triggered by changes in assimilate partitioning. Seed set would be expected to create a strong sink for assimilates. It is feasible that assimilates were translocated from the petals to the developing ovules, thereby accelerating flower senescence.

Our rationale for removing styles in Expt. 6 rather than emasculating flowers was based on the fact that pollen is shed on or about the day of anthesis (Expt. 2). We reasoned that emasculation on the day of anthesis would not prevent autogamy and may actually increase pollen dispersal during anther removal, whereas removal of the style would prevent pollen tubes from reaching the ovary. Among flowers in which the style was removed, there was no significant difference in longevity between plants treated with 2 mm STS and those treated with deionized water (Expt. 6). 
Hence, removal of styles had a minimal effect on $\mathrm{C}_{2} \mathrm{H}_{4}$ evolution and/or increasing the sensitivity to $\mathrm{C}_{2} \mathrm{H}_{4}$.

IMPLICATIONS FOR BREEDING. Autopolyploidy has been used as a means of obtaining large flowers and strong stems in many floricultural crops (Sparnaaij, 1979), and yields similar benefits in Easter cactus. Autopolyploid clones of Easter cactus, however, would be less desirable if their flowers were short-lived as a consequence of SC. Although experimentally effective, removal of styles at anthesis is an impractical method for extending flower longevity in SC tetraploid clones. The most effective means of maximizing flower longevity in SC tetraploids is to select genotypes that do not self-pollinate during the early stage of floral development. We have shown that SC clones differ in the stage of floral development in which autogamy commences. Hence, it is possible for breeders to select SC tetraploid clones like 'Purple Pride' variant with large, long-lived flowers.

\section{Literature Cited}

Ascher, P.D. 1984. Self-incompatibility, p. 92-110. In: K.C. Sink (ed.). Petunia. Springer, Berlin.

Beyer, Jr., E.M. 1976. A potent inhibitor of ethylene action in plants. Plant Physiol. 58:268-271.

Boyle, T.H. 1994. A simple method for extracting and cleaning seeds of Rhipsalidopsis and Schlumbergera (Cactaceae). HortTechnology 4:264 265.

Boyle, T.H. 1997a. Holiday and Easter cactus, p. 82-88. In: M.L. Gaston, S.A. Carver, C.A. Irwin, and R.A. Larson (eds.). Tips on growing specialty potted crops. Ohio Florists' Assn., Columbus, Ohio.

Boyle, T.H. 1997b. The genetics of self-incompatibility in the genus Schlumbergera (Cactaceae). J. Hered. 88:209-214.

Boyle, T.H., F.D. Menalled, and M.C. O'Leary. 1994. Occurrence and physiological breakdown of self-incompatibility in Easter cactus. J. Amer. Soc. Hort. Sci. 119:1060-1067.

de Nettancourt, D. 1977. Incompatibility in angiosperms. Springer, Berlin. Ganders, F.R. 1976. Self-incompatibility in the Cactaceae. Cactus Suc- culent J. Great Britain 38:39-40.

Gilissen, L.J.W. 1977. Style-controlled wilting of the flower. Planta 133:275-280

Gilissen, L.J.W. and F.A. Hoekstra. 1984. Pollination-induced corolla wilting in Petunia hybrida rapid transfer through the style of a wiltinginducing substance. Plant Physiol. 75:496-498.

Halevy, A.H., C.S. Whitehead, and A.M. Kofranek. 1984. Does pollination induce corolla abscission of cyclamen flowers by promoting ethylene production? Plant Physiol. 75:1090-1093.

Han, S.S. and T.H. Boyle. 1996. Ethylene affects postproduction quality of Easter cactus. J. Amer. Soc. Hort. Sci. 121:1174-1178.

Karle, R. 1996. The influence of polyploidy on the morphology, physiology, and breeding behavior of Hatiora $\times$ graeseri (Cactaceae). MS thesis. Univ. of Mass., Amherst.

Lovell, P.J., P.H. Lovell, and R. Nichols. 1987. The control of flower senescence in petunia (Petunia hybrida). Ann. Bot. 60:49-59.

Martin, F.W. 1959. Staining and observing pollen tubes in the style by means of fluorescence. Stain Technol. 34:125-128.

Nichols, R. and C.E. Frost. 1985. Post-harvest effects on ethylene on ornamental plants, p. 343-351. In: J.A. Roberts and G.A. Tucker (eds.). Ethylene and plant development. Butterworths, London.

Ross, R. 1981. Chromosome counts, cytology, and reproduction in the Cactaceae. Amer. J. Bot. 68:463-470.

SAS Institute Inc. 1987. SAS/STAT guide for personal computers. version 6 ed. SAS, Cary, N.C.

Scott, D., T.H. Boyle, and S.S. Han 1994. Floral development and flower longevity in Rhipsalidopsis and Schlumbergera (Cactaceae). HortScience 29:898-900.

Singh, A., K.B. Evensen, and T-h Kao. 1992. Ethylene synthesis and floral senescence following compatible and incompatible pollinations in Petunia inflata. Plant Physiol. 99:38-45.

Sparnaaij, L.D. 1979. Polyploidy in flower breeding. HortScience 14:496499.

Whitehead, C.S., A.H. Halevy, and M.S. Reid. 1984. Roles of ethylene and 1-aminocyclopropane-1-carboxylic acid in pollination and wound-induced senescence of Petunia hybrida flowers. Physiol. Plant. 61:643648 . 